\title{
Study of First Seizure in 2 Month to 18 Years Old Children Presenting At a Tertiary Care Hospital of Meghalaya
}

\author{
Dr. Salil Srivastava ${ }^{1 *}$, Dr. Palash R Gogoi ${ }^{2}$, Dr. Prasenjit Paul ${ }^{3}$, Dr. Santanu Deb ${ }^{4}$
}

\author{
${ }^{1}$ DNB Pediatric Senior Resident, Department of Pediatrics \& Neonatology, Nazareth Hospital, Shillong- 793003, Meghalaya, India \\ ${ }^{2}$ Senior Consultant, Department of Pediatrics \& Neonatology, Nazareth Hospital, Shillong- 793003, Meghalaya, India \\ ${ }^{3}$ Senior Consultant, Department of Pediatrics \& Neonatology, Nazareth Hospital, Shillong- 793003, Meghalaya, India \\ ${ }^{4}$ Senior Consultant and HOD, Department of Pediatrics \& Neonatology, Nazareth Hospital, Shillong- 793003, Meghalaya, India
}

DOI: $10.36347 /$ sjams.2020.v08i07.005

| Received: 20.07.2020 | Accepted: 27.07.2020 | Published: 05.08.2020

*Corresponding author: Salil Srivastava

Abstract

Original Research Article

Objective: Aim was to find out the prevalence of provoked seizures, etiology, types of seizure and the immediate outcome in children 2 months to 18 years presenting with first episode of seizure. Methods: This was a Prospective Cross Sectional Observational hospital based study carried out in Nazareth Hospital, Shillong. All children 2 months up to 18 years of age admitted in the Department of Pediatrics, Nazareth Hospital, Shillong, Meghalaya, India presenting with first episode of seizure were included in the study. Results: A total of 80 patients were included in the study, $57 \%$ were male and $43 \%$ were female. Most of the cases, $(72.5 \%)$ belonged to the age group 2 months to $<5$ years of age and were from rural area $(60 \%)$. Fever was present in $78.7 \%$ of the patients. GTCS $(87 \%)$ was the most common clinical type of seizure followed by focal seizures which was $13 \%$ ( $p<0.001$ ). $77 \%$ of the seizures in the enrolled patients were provoked seizures and febrile convulsion (49\%) was the commonest etiology of provoked seizure, followed by acute infarct, neurocysticercosis and $21 \%$ patients had seizure disorder. In $84 \%$ of the provoked seizures, fever was the provoking factor $(\mathrm{p}<0.03)$. Of the total 1495 admission during the study period of one year $\left(1^{\text {st }}\right.$ January to $31^{\text {st }}$ December 2017), 110 children presented with the first episode of seizure. Thus prevalence in our study was 7.35. Conclusions: In our study, of the 80 enrolled children with first episode of seizures, majority of the seizures were provoked seizures, GTCS type, children belonging to 2 months to 5 years age group were mainly affected, with male predominance and fever was found to be the most common provoking factor for seizure.

Keywords: Seizures, Febrile seizures, Provoked seizure, Epilepsy, Hospital, Pediatric.

Copyright @ 2020: This is an open-access article distributed under the terms of the Creative Commons Attribution license which permits unrestricted use, distribution, and reproduction in any medium for non-commercial use (NonCommercial, or CC-BY-NC) provided the original author and source are credited.

\section{INTRODUCTION}

A seizure is a transient occurrence of sign and symptoms resulting from abnormal excessive or synchronous neuronal activity in the brain. Seizures broadly can be divided into two large categories namely, generalized and focal. Focal seizures denote activation of neurons activation of one part of cerebral hemisphere whereas generalized seizures indicate synchronous involvement of all of both hemisphere [1].

Approximately $4-10 \%$ of children experience at least one seizure (febrile or afebrile) in the first 16 years of life [2]. The incidence is highest in children younger than 3 years of age, with a decreasing frequency in older children [3]. Epidemiologic studies reveal that approximately 150,000 children will sustain a first-time, unprovoked seizure each year, and of those, 30,000 will develop epilepsy [2]. Seizure disorder is a general term that is usually used to include any one of the several disorders, including epilepsy, febrile seizures and possible single seizures and symptomatic seizure secondary to metabolic, infection or other etiologies (e.g. hypocalcemia, meningitis). Epilepsy is a disorder of the brain characterized by an enduring predisposition to generate seizure and by the neuro biologic, cognitive, psychological and social consequence of this condition [1]. Provoked seizures occur secondary to an acute problem affecting brain excitability such as electrolyte disturbance [1]. An unprovoked seizure is one that is not an acute symptomatic seizure [1].

\section{Need for this Study}

There is paucity of data regarding the prevalence and occurrence of seizures in children from north-east India especially Meghalaya. Also the various etiologies of the first seizure, and possible future outcome of the seizure episode may not be similar to other populations in India and other parts of the world. 


\section{AIM}

To find out the following with regards to the first seizure in children in the age group of 2 months to 18 years:-

1. Prevalence of provoked seizure

2. Etiology of seizure

3. Type of seizure

4. Immediate outcome

\section{METHODS}

This study was conducted in the Department of Pediatrics \& neonatology, Nazareth Hospital, which is a private post graduate teaching hospital in Shillong, Meghalaya, India. This is a Prospective Cross Sectional Observational hospital based study. Sample size has been calculated using the following formula where: $\mathrm{n}=\mathrm{Z}_{1-\square / 2 \mathrm{P}}^{2}(1-\mathrm{P}) / \mathrm{d}^{2}$ where Alpha:-level of significance, Z:-1.96, Alpha: - 5\%, P:-84\%, d:-8\%. Sample size was calculated to be 80 . Study duration was one year from $1^{\text {st }}$ January 2017 to $31^{\text {st }}$ December 2017 . All children 2 months up to 18 years of age admitted in the Department of Pediatrics, Nazareth Hospital, Shillong, Meghalaya presenting with first episode of seizure were included in the study. Children who expired before clinical and diagnostic workup could be completed and those in whom a reliable history was not available were excluded from the study. Ethical approval for conducting this study was obtained from institutional ethics committee. All children were enrolled only after obtaining informed consent from parent/ guardian. Demographic data such as age, sex, place of residence, socio economic status etc were recorded. Detailed history and physical examination including a thorough neurological examination were conducted on enrolled children. Relevant investigations such as routine blood investigations, biochemical tests such as blood sugar, electrolytes, CSF examination, neuroimaging etc. were done as per department protocol. Neuroimaging and CSF analysis were not done in all enrolled patients and were guided by the clinical condition of the patient. Standard protocols were followed in deciding the need for these investigations.

\section{Statistical Analysis}

Data was entered in SPSS Version 22.0. The tests used for analysis are Percentage Analysis, Large sample tests, Chi-square test of association and Fisher's test.

\section{RESULTS}

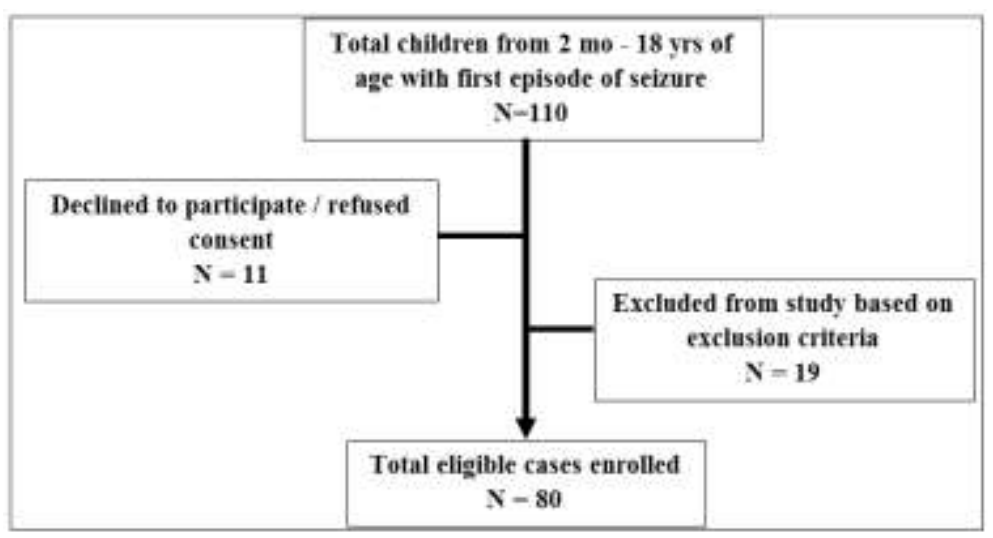

Fig-1: Study flow chart

Total cases enrolled in the study were 80 . Fifty eight $(72.5 \%)$ cases with first episode of seizure belonged to the age group of 2 months to $<5$ years and association with age was found to be statistically significant $(\mathrm{p}<0.0001)$. In this study, $46(57 \%)$ cases with first episode of seizure were male, $34(43 \%)$ of cases were female.

Table-1: Distribution of enrolled subjects according to the different age groups

\begin{tabular}{|l|l|l|l|l|l|l|}
\hline \multirow{2}{*}{ FEVER } & \multicolumn{5}{|c|}{ AGE } \\
\cline { 2 - 7 } & $\begin{array}{l}\text { 2 MONTH - <5 YEARS } \\
(\mathbf{N}=\mathbf{5 8})\end{array}$ & $\begin{array}{l}\text { 5 YEARS TO <12 YEARS } \\
\text { (N=16) }\end{array}$ & $\begin{array}{l}\text { 12 YEARS TO 18 YEARS } \\
\text { (N=6) }\end{array}$ \\
\cline { 2 - 7 } & $\begin{array}{l}\text { Number } \\
\text { of Patients }\end{array}$ & Percentage & $\begin{array}{l}\text { Number of } \\
\text { Patients }\end{array}$ & Percentage & $\begin{array}{l}\text { Number of } \\
\text { Patients }\end{array}$ & Percentage \\
\hline FEVER PRESENT & 50 & $86.2 \%$ & 11 & $68.8 \%$ & 2 & $33.3 \%$ \\
\hline FEVER ABSENT & 8 & $13.8 \%$ & 5 & $31.3 \%$ & 4 & $66.7 \%$ \\
\hline & $\mathrm{p}<0.001$ & $\mathrm{p}=0.16$ & $\mathrm{p}=0.44$ & \\
\hline
\end{tabular}

It was seen in this study that $48(60 \%)$ cases were from rural area and $32(40 \%)$ from urban area. This difference was found to be statistically significant
( $\mathrm{p}<0.007)$. In total 58 cases with first episode of seizure in the age group 2 months to $<5$ years, $50(86.2 \%)$ cases were with fever and in only $8(13.8 \%)$ cases, fever 
was absent. This difference was found to be statistically significant $(\mathrm{p}<0.001)$. Majority of first episodes of seizure that were associated with fever were present in 2 months to 5 years age group. $77 \%$ of the first episode of seizures were provoked and $23 \%$ were unprovoked. This difference was found to be statistically significant $(\mathrm{p}<0.001)$

In $84 \%$ of first episode of provoked seizures, fever is the provoking factor. This has been found to be statistically significant $(\mathrm{p}<0.03$ ). Generalized tonic clonic seizure was found to be the predominant type of seizure. GTCS occurred in $83 \%$ patients of first episode of seizure and focal seizures occurred in $13 \%$ and this difference was found to be statistically significant ( $\mathrm{p}$ $<0.001)$.

Of all the patients who had first episode of seizure along with fever, $90.50 \%$ had GTCS and $9.50 \%$ had focal seizures and this difference was found to be statistically significant $(p<0.03)$ using the test of independence.

Out of total 80 patients of first episode of seizure, CSF analysis was indicated and performed for 58 patients (72\%). CSF analysis was not required for 22 patients. CSF analysis was abnormal in $13.8 \%$ of cases, all of whom were in the age group 2 months to < 5years of age.
CT scan brain was indicated and performed in 38 children. In this study, haemorrhage and infarct were the abnormalities that were found in $6(30 \%)$ of 20 children and $1(2 \%)$ of 20 children in the age group of 2 mo to $<5$ yrs for whom CT scan was performed. NCC was present only in $6(33.3 \%)$ out of 18 children above 5 years of age for whom CT scan was performed. Out of the 6 patients of infarcts in the 2 mo to $<5$ yrs age group, 3 had Leigh disease (bilateral basal ganglia infarct).

EEG was performed for 24 patients, of whom $17(70.83 \%)$ patients had abnormal EEG.

Febrile convulsion was the commonest diagnosis in this study with (49\%) of patients presenting with fever and convulsion. The other common diagnosis were seizure disorder $(21 \%)$ and meningo encephalitis with acute infarct (11.4\%).

On analysis of immediate outcome, it was found that $3(3.75 \%)$ patients died, $13(16 \%)$ were discharged with sequelae, while $64(80 \%)$ recovered and were discharged without sequelae. The various sequelae with which the patients were discharged included global developmental delay, various focal neuro deficits.

\begin{tabular}{|c|c|c|c|}
\hline & \multirow[t]{3}{*}{ DIAGNOSIS } & \multicolumn{2}{|l|}{ TYPE OF SEIZURE } \\
\hline & & GTCS & FOCAL \\
\hline & & Number of Patients $(\mathrm{N}=70)$ & Number of Patients $(\mathrm{N}=10)$ \\
\hline 1 & Febrile convulsion & $34(49 \%)$ & 0 \\
\hline 2 & Neurocystecercosis & $0(0 \%)$ & $6(60 \%)$ \\
\hline 3 & Meningoencephalitis & $6(9 \%)$ & $1(10 \%)$ \\
\hline 4 & Sturge weber syndrome & $0(0 \%)$ & $1(10 \%)$ \\
\hline 5 & Seizure disorder & $15(21.4 \%)$ & $2(20 \%)$ \\
\hline 6 & Meningitis & $3(4 \%)$ & 0 \\
\hline 7 & Severe sepsis & $7(10)$ & 0 \\
\hline 8 & TB meningitis & $2(2.8 \%)$ & 0 \\
\hline 9 & Meningitis with hydrocephalus with incranial bleed & $1(1.4 \%)$ & 0 \\
\hline 10 & Shigella encephalopathy & $1(1.4 \%)$ & 0 \\
\hline 11 & $\begin{array}{l}\text { Post Infectious Glomerulonephritis with hypertensive } \\
\text { encephalopathy }\end{array}$ & $1(1.4 \%)$ & 0 \\
\hline
\end{tabular}

Table-3: Distribution of enrolled patients according the occurrence of neuro-sequelae

\begin{tabular}{|c|c|c|c|}
\hline \multirow{3}{*}{ DIAGNOSIS } & \multicolumn{3}{|l|}{ SEQUELAE } \\
\hline & Without sequelae & With sequelae & Died \\
\hline & Number of Patients & Number of Patients & Number of Patients \\
\hline Febrile convulsion & 34 & 0 & 0 \\
\hline Seizure disorder & 17 & 0 & 0 \\
\hline Neurocysticercosis & 6 & 0 & 0 \\
\hline Meningoencephalitis & 2 & 4 & 1 \\
\hline Severe sepsis & 5 & 1 & 1 \\
\hline Meningitis & 2 & 1 & 0 \\
\hline PIGN with hypertensive encephalopathy & 1 & 0 & 0 \\
\hline Meningitis with hydrocephalus with intracranial bleed & 0 & 0 & 1 \\
\hline Shigella Encephalopathy & 1 & 0 & 0 \\
\hline TB Meningitis & 1 & 1 & 0 \\
\hline Sturge Weber Syndrome & 0 & 1 & 0 \\
\hline
\end{tabular}


Salil Srivastava et al., Sch J App Med Sci, August, 2020; 8(8): 1823-1827

Table-4: Distribution of enrolled patients according to the association of fever and clinical types of seizure and relation to provoked seizures

\begin{tabular}{|c|c|c|c|c|c|c|}
\hline \multirow{3}{*}{\multicolumn{2}{|c|}{ VARIABLES }} & \multicolumn{4}{|c|}{ CATEGORY OF SEIZURE } & \multirow[t]{3}{*}{ p value } \\
\hline & & \multicolumn{2}{|c|}{ PROVOKED } & \multicolumn{2}{|l|}{ UNPROVOKED } & \\
\hline & & Number of Patients & Percentage & Number of Patients & Percentage & \\
\hline \multirow[t]{2}{*}{ Gender } & MALE & 36 & $76.1 \%$ & 10 & $23.9 \%$ & \multirow[t]{2}{*}{0.17} \\
\hline & FEMALE & 27 & $79.4 \%$ & 7 & $20.6 \%$ & \\
\hline \multirow[t]{3}{*}{ Age } & $2 \mathrm{MONTH}-<5$ YEARS & 51 & $86.2 \%$ & 7 & $13.8 \%$ & $<0.001$ \\
\hline & 5YEAR TO <12 YEAR & 9 & $56.3 \%$ & 7 & $43.8 \%$ & 0.16 \\
\hline & 12 YEARS TO 18 YEARS & 3 & $50.0 \%$ & 3 & $50.0 \%$ & 0.44 \\
\hline \multirow[t]{2}{*}{ Fever } & FEVER PRESENT & 53 & $82.5 \%$ & 10 & $17.5 \%$ & \multirow[b]{2}{*}{$<0.03$} \\
\hline & FEVER ABSENT & 10 & $58.8 \%$ & 7 & $41.2 \%$ & \\
\hline \multirow{2}{*}{$\begin{array}{l}\text { Type } \\
\text { Of Seizure }\end{array}$} & GTCS & 55 & $69 \%$ & 15 & $11 \%$ & \multirow[b]{2}{*}{$<0.001$} \\
\hline & FOCAL & 8 & $80.0 \%$ & 2 & $20.0 \%$ & \\
\hline
\end{tabular}

\section{DISCUSSION}

This study was a hospital based prospective study of children with first episode of seizure admitted in the department of Pediatrics \& Neonatology, Nazareth Hospital, a tertiary care centre in the Shillong, the capital of the state of Meghalaya in the north eastern region of India from $1^{\text {st }}$ January 2017 to $31^{\text {st }}$ December 2017.

\section{Prevalence}

Total admissions during the study period were 1495 (patients aged 2 months to 18 years), out of which 213 were patients with seizure and 110 were patients with first episode of seizure . Hence, prevalence of first episode of seizure in 2 month to 18 years of age in our study was $7.3 \%$ in the year 2017, which is similar to the study conducted by Adhikari et al., [4].

The prevalence in our study was higher as compared to $2.1 \%$ in a study by Gogoi et al., [6], and $2 \%$ in other similar studies [5, 7-11] and $1 \%$ by Chen $e t$ al., [12].

\section{Clinical Seizure Type}

In our study GTCS (83\%) was more common than focal seizures (13\%), with which patients presented to hospital. This difference was found to be statistically significant $(\mathrm{p}<0.001)$. Similar higher prevalence of GTCS was also obtained in other studies [5-13]. The prevalence of focal seizures (13\%) were more common as compared to study by Gogoi et al., in which focal seizure was (9.2\%) [5], but it is much less than $19.8 \%$ [10] of focal seizure found in study by Adhikari et al., [4] probably due to high incidence of neurocysticercosis $(7.5 \%)$.

\section{Etiological Profile}

In our study, $77 \%$ cases of first episode of seizure were provoked seizures and this proves the hypothesis of the study. This result was found to be statistically significant $(\mathrm{p}<0.001)$. This signifies that most of the seizures are provoked due to some underlying cause.
This result is similar to other studies, such as a prevalence of $75 \%$ in the study conducted by Jan et al., [14], 83\% by Gogoi et al., [6] similar higher prevalence is present in the study by Martindale et al., [5].

Febrile convulsion (49\%) is the most common etiology for the first episode of seizure in children, followed by seizure disorder, meningoencephalitis and neurocysticercosis. While in older age group, seizure disorder and neurocysticercosis were found to be the most common etiology for first episode of seizure.

\section{Immediate Outcome}

In our study, 3 patients died, 13 were discharged with sequelae, while 64 recovered and were discharged without sequelae. The various sequelae with which the patients were discharged included global developmental delay, various focal neuro deficits etc.

Mortality in our study was $3.7 \%$ which is similar to the study conducted by Adhikari et al., [4] $3.1 \%$ in the study by Idro et al., [7] while it is much less as compared to study conducted by Gogoi et al, which has mortality of $9.2 \%$ [6].

Febrile seizure, neurocysticercosis, seizure disorder, hypertensive encephalopathy and Shigella encephalopathy had no neurological sequelae and were discharged after recovery.

\section{LIMITATIONS}

Nazareth hospital caters to Class 3 and Class 4 population according to modified Kuppuswamy socioeconomic scale and due to resource constraint, complete investigations to identify causes like inborn errors of metabolism and other syndromic evaluation could not be done.

This study was conducted for a period of 1 year and therefore study population was less. In our study only immediate outcome was considered, therefore scholastic performance and neurological dysfunction could not be studied. 
Epilepsy requires long term follow up for recurrence of seizures to occur and it cannot be diagnosed with first episode of seizure.

\section{Conclusion}

In our study, of the 80 enrolled children with first episode of seizures, majority of the seizures were provoked seizures, GTCS type, children belonging to 2 months to 5 years age group were mainly affected, with male predominance and fever was found to be the most common provoking factor for seizure.

\section{REFERENCES}

1. Kleigman RM, Stanton BF, Nelson SNF. Textbook Of Pediatrics. 20th ed. 2016. 2823-2838.

2. McAbee GN, Wark JE. A practical approach to uncomplicated seizures in children. Am Fam Physician. 2000 Sep;62(5):1109-16.

3. Vining EP. Pediatric seizures. Emerg Med Clin North Am. 1994 Nov;12(4):973-88.

4. Adhikari S, Sathian B, Koirala DP, Rao KS. Profile of children admitted with seizures in a tertiary care hospital of Western Nepal. BMC Pediatr. 2013 Mar; 13:43.

5. Martindale JL, Goldstein JN, Pallin DJ. Emergency department seizure epidemiology. Emerg Med Clin North Am. 2011 Feb;29(1):1527.

6. Gogoi A, Islam AK, Panyang R, Dowerah P, Ramasamy S, Boruah M. A prospective hospital based study on the clinico-etiological profile of first episode seizures in children. Int $\mathrm{J}$ Med Res
Prof. 2016;2(3):108-4.

7. Freidman Marla J SGQ. Seizures in Children. Pediatric Clinics of North America. 53rd ed. 2006. 257-277.

8. Pallin DJ, Goldstein JN. Seizure visits in US emergency departments: epidemiology and potential disparities in care. 2008; 97-105.

9. Huff JS, Morris DL, Kothari RU, Gibbs MA. Emergency department management of patients with seizures: a multicenter study. Acad Emerg Med. 2001 Jun;8(6):622-8.

10. Sharma S, Riviello JJ, Harper MB, Baskin MN. The role of emergent neuroimaging in children with new-onset afebrile seizures. Pediatrics. 2003 Jan;111(1):1-5.

11. Choquet C, Depret-Vassal J, Doumenc B, Sarnel S, Casalino E. Predictors of early seizure recurrence in patients admitted for seizures in the Emergency Department. European Journal of Emergency Medicine. 2008 Oct 1;15(5):261-7.

12. Tilelli JA, Ophoven JP. Hyponatremic seizures as a presenting symptom of child abuse. Forensic Sci Int. 1986;30(2-3):213-7.

13. Chen C, Chang Y, Wu H. New-onset Seizures in Pediatric Emergency. Pediatr Neonatol. 2010; 51(2):103-11.

14. Muzafar J, Suhail N, Bilal A, Ahmad K. Incidence and etiology of acute symptomatic seizures in children in the age group 1 month to 6 years in Kashmir North India. Journal of Evolution of Medical and Dental Sciences. 2015 Jun 8;4(46):7960-8. 